\title{
Water and Brines on Mars: Current Evidence and Implications for MSL
}

\author{
G.M. Martínez • N.O. Renno
}

Received: 2 September 2012 / Accepted: 11 December 2012 / Published online: 11 January 2013

(C) The Author(s) 2013. This article is published with open access at Springerlink.com

\begin{abstract}
Liquid water is a basic ingredient for life as we know it. Therefore, in order to understand the habitability of other planets we must first understand the behavior of water on them. Mars is the most Earth-like planet in the solar system and it has large reservoirs of $\mathrm{H}_{2} \mathrm{O}$. Here, we review the current evidence for pure liquid water and brines on Mars, and discuss their implications for future and current missions such as the Mars Science Laboratory.

Neither liquid water nor liquid brines are currently stable on the surface of Mars, but they could be present temporarily in a few areas of the planet. Pure liquid water is unlikely to be present, even temporarily, on the surface of Mars because evaporation into the extremely dry atmosphere would inhibit the formation of the liquid phase, where the temperature and pressure are high enough so that water would neither freeze nor boil. The exception to this is that monolayers of liquid water, referred to as undercooled liquid interfacial water, could exist on most of the Martian surface. In a few places liquid brines could exist temporarily on the surface because they could form at cryogenic temperatures, near ice or frost deposits where sublimation could be inhibited by the presence of nearly saturated air.

Both liquid water and liquid brines might exist in the shallow subsurface because even a thin layer of soil forms an effective barrier against sublimation allowing pure liquid water to form sporadically in a few places, or liquid brines to form over longer periods of time in large portions of the planet. At greater depths, ice deposits could melt where the soil conductivity is low enough to blanket the deeper subsurface effectively. This could cause the formation of aquifers if the deeper soil is sufficiently permeable and an impermeable layer exists below the source of water.

The fact that liquid brines and groundwater are likely to exist on Mars has important implications for geochemistry, glaciology, mineralogy, weathering and the habitability of Mars.
\end{abstract}

Keywords Brines · Mars · Water

G.M. Martínez (凶) · N.O. Renno

Department of Atmospheric, Oceanic, and Space Sciences, University of Michigan, Ann Arbor, MI, USA

e-mail: gemartin@umich.edu 


\section{Introduction}

The water vapor pressure at the triple point of water is below the present day atmospheric pressure on the lowest regions of Mars, including the Mars Science Laboratory (MSL) landing site on Gale Crater. However, the low surface temperature and dry air of these regions inhibit the presence of bulk amounts of liquid water on the surface (Haberle et al. 2001). On the other hand, liquid brines can be present where a source of water exists (e.g., near-surface ground ice) because salts depress the freezing temperature below the present day temperatures at the surface of Mars (Farmer 1976; Clark 1978; Brass 1980; Clark and Van Hart 1981; Moore and Bullock 1999; Bryson et al. 2008; Haberle et al. 2001; Rao et al. 2005; Chevrier and Altheide 2008; Rennó et al. 2009b). In addition, monolayers of unfrozen water, referred to as undercooled liquid interfacial (ULI) water, can be present at the surface and in the shallow subsurface $(\leq 1 \mathrm{~m}$ ) (Möhlmann 2004), and groundwater can be present in the deep subsurface ( $\geq 100 \mathrm{~m}$ ) (Goldspiel and Squyres 2011).

The MSL Curiosity Rover is equipped with optical and analytical instruments (Grotzinger et al. 2012) capable of detecting evidence for liquid water and brines on Gale Crater. These instruments include: (i) the Rover Environmental Monitoring Station developed to measure atmospheric pressure, atmospheric humidity, ground and atmospheric temperatures, and UV radiation fluxes (Gómez-Elvira et al. 2012); (ii) the Sample Analysis at Mars suite (SAM) developed to analyze the atmospheric composition and volatiles from soil samples, including water vapor (Mahaffy et al. 2012); (iii) the Dynamic Albedo of Neutrons (DAN) instrument developed to measure the subsurface hydrogen content down to about one meter below the surface (Mitrofanov et al. 2012); (iv) the Mast Camera (MastCam) developed to image the rover's surroundings in high-resolution stereo and color; (v) the Chemistry and Camera (ChemCam) instrument developed to vaporize thin layers of material from Martian rocks and soils with a laser beam to identify the elements excited by it, and a telescope to capture detailed images of the area analyzed (Maurice et al. 2012); (vi) the Chemistry and Mineralogy (CheMin) instrument developed to identify and characterize the mineralogy of rocks and soils (Blake et al. 2012); (vii) the Alpha Particle X-ray Spectrometer (APXS) developed to determine the relative abundances of different elements in rocks and soils (Campbell et al. 2012); (viii) the Mars Hand Lens Imager (MAHLI) developed to take close-up images of rocks, soils and, if present, water ice and brines (Edgett et al. 2012); and a few other instruments including engineering cameras (ECAM) (Maki et al. 2012) capable of detecting evidence for frost and deliquescence if it occurs near the rover.

The detection of hydrogen may indicate the presence of water in the form of ice or bound to minerals, while the detection of the various elements expected in brine candidates, in the expected proportion, would provide circumstantial evidence for their existence on Gale Crater. The detection of high hydrogen content would suggest the existent of water ice or brines in the shallow subsurface. If circumstantial evidence for brines were found, it could be investigated in detail with analytical instruments such as SAM, CheMin and APXS, as well as with cameras such as MAHLI, MastCam and ECAM.

The existence of either liquid water or liquid brines on Mars is important because their presence would have significant implications for our understanding of the geochemistry, glaciology, mineralogy, weathering and habitability of the red planet. Indeed, liquid water is essential for life as we know it and many microorganisms thrive in terrestrial brines in favorable ranges of water activity, particularly in brines found in subglacial environments (Mikucki et al. 2009). The presence of bulk amounts of pure water or brines near the surface would also facilitate human missions to Mars. In this article, we study the necessary conditions for liquid water and liquid brines to exist on Mars and review the observational evidence for them. 


\section{Theoretical Expectations for Liquid Water on Mars}

In this section we show that pure liquid water is currently unstable in bulk amounts on the surface of Mars, but that in a few places it could exist temporarily. We also show that this is unlikely to occur, with perhaps the exception of a few locations with favorable surface topography and optical properties, under favorable meteorological conditions. However, liquid water could exist: (i) as monolayers of ULI water on the surface, shallow subsurface $(\leq 1 \mathrm{~m})$, and deep subsurface $(\geq 100 \mathrm{~m})$, (ii) as liquid brines both on the surface and the shallow and deep subsurface, (iii) as melt water formed by solid-state greenhouse effect in the shallow subsurface, and (iv) as groundwater or aquifers (possibly of liquid brines) in the deep subsurface.

\subsection{Bulk Pure Liquid Water on the Surface}

Bulk pure liquid water is not currently stable on the surface of Mars, but thermodynamics indicate that it could form temporarily on a substantial portion of the planet if the air were not as dry as it is today. Here we study the conditions under which bulk amounts of pure liquid water could exist temporarily on the surface of Mars.

Pure liquid water can exist only where the water temperature and the atmospheric pressure are above those of the triple point of water (273.16 K, 611.73 Pa) (Fig. 1). In addition, in order for pure liquid water to exist for significant periods of time, it must be stable against freezing, boiling, and evaporation. Pure liquid water is stable against freezing at temperatures above $273.16 \mathrm{~K}$, regardless of the atmospheric pressure (Fig. 1). Similarly, pure liquid water is stable against boiling if the atmospheric pressure is above the saturation vapor pressure at the temperature of the water. For example, at $275 \mathrm{~K}$ the atmospheric pressure has to exceed $698 \mathrm{~Pa}$ for boiling to be prevented and pure liquid water to be stable.

If only stability against freezing and boiling are considered, pure liquid water can exist over about $29 \%$ of the surface of Mars, and can last up to 37 Sols in a few places (Haberle et al. 2001). The conditions for pure liquid water to exist, indicated in Fig. 1, are met temporarily on Arabia Terra, Amazonis Planitia, and Elysium Planitia in the northern latitude belt extending from $0^{\circ}$ to $30^{\circ} \mathrm{N}$, and at Hellas and Argyre Planitia in the southern hemisphere, extending down to $50^{\circ} \mathrm{S}$. However, pure liquid water is not stable against evaporation in these regions. Thus, bulk pure liquid water is unlikely to be found on the surface of Mars because it would quickly evaporate when exposed to the dry atmosphere in the most favorable regions where it neither freezes nor boils.

In order for pure liquid water to be stable against evaporation, the partial pressure of water vapor must be higher than the saturation water vapor pressure at the temperature of the water. In the current climate, this condition is never satisfied on the surface of Mars. Indeed, in the current climate the partial pressure of water vapor at the surface of Mars is below 1 Pa (Zent et al. 2010; Jones and Lineweaver 2012; Savijärvi and Määttänen 2010). This value is two orders of magnitude lower than the saturation water vapor pressure at the triple point $(611.73 \mathrm{~Pa})$. Thus, only the buffering of this difference in water vapor pressure could allow pure liquid water to be stable on the surface. Currently, there is no evidence for processes that could produce such buffers on the surface of Mars and therefore liquid water is unlikely to occur at the surface.

Given that pure liquid water is not stable on the surface of Mars, can it at least form temporarily? For this to occur, the condensation of atmospheric water vapor at rates larger than the evaporation rate, or the melting of ice at rates larger than the evaporation rate must occur. Condensation can be ruled out because the partial pressure of water vapor on Mars is 


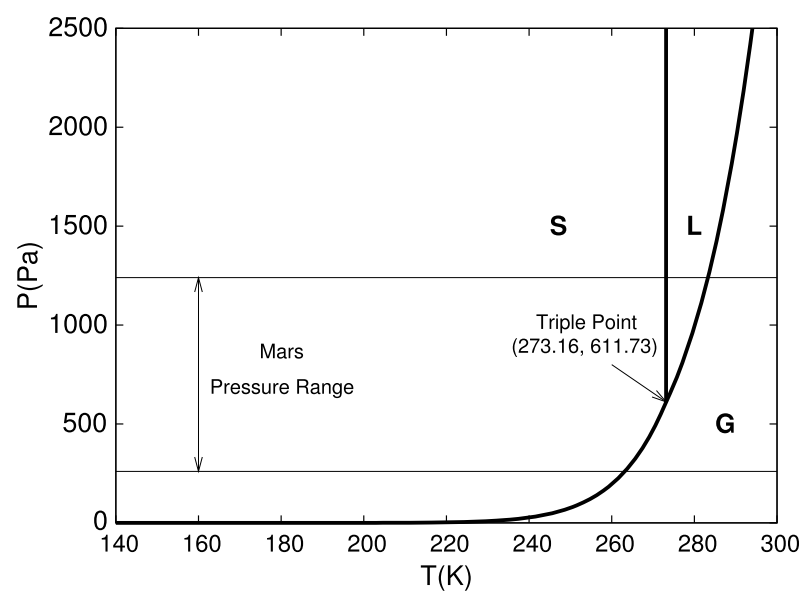

Fig. 1 Phase diagram of pure water substance indicating the current atmospheric pressure range on the surface of Mars. The liquid phase can exist on Mars only at temperatures above the triple point, but below an upper limit determined by the local atmospheric pressure, otherwise it would boil. This condition is met temporarily over about $29 \%$ of the surface of Mars (Haberle et al. 2001). Pure liquid water is stable against freezing and boiling in this area, but not against evaporation. Indeed, pure liquid water is unstable on the surface of Mars because even in this area it would quickly evaporate when exposed to the dry atmosphere. Thus, only transient events such the melting of ice can produce pure liquid water temporarily on the surface of Mars. We show that these events are unlikely to occur, with perhaps the exception of a few locations with favorable surface topography and optical properties, under favorable meteorological conditions

at least two orders of magnitude lower than the saturation water vapor pressure at the triple point. The melting of ice, although thermodynamically possible, is unlikely to occur unless favorable meteorological conditions occur at locations with extremely favorable surface topography and optical properties. For ice to melt, two conditions must be satisfied. First, ice must be present on the surface or in the shallow subsurface of the five candidate regions that meet the range of conditions indicated in Fig. 1. This is a problem because ice is not stable on the three northern near-equatorial regions, and likely also not stable at the two southern higher-latitude regions (Mellon et al. 2004) that meet these conditions temporarily. Second, the peak solar heating must overcome the sum of the heat-losses processes of the ice. Under the typical Martian conditions indicated in Table I of Hecht (2002), the evaporative, radiative, and conductive losses can independently exceed the solar heating and thus prevent ice from melting. However, Hecht (2002) shows that the melting of ice might be possible on slopes facing the sun, under clear sky and calm wind conditions, at locations with low surface albedo and low soil conductivity.

\subsection{Monolayers of Liquid Water, Brines, and the Subsurface}

The conditions for the existence of liquid water on Mars are relaxed if the subsurface and other forms of water are considered. Here we present a comprehensive description of the different forms of liquid water likely to exist on Mars: ULI water, subsurface melt water, liquid brines, and groundwater. We define each of them, discuss their importance, give evidence for their presence, explain the physics governing their formation, and finally discuss the locations on Mars where they are most likely to exist today. 


\subsubsection{Undercooled Liquid Interfacial Water}

ULI water refers to physisorbed water in a liquid-like state, at temperatures below the freezing point. Physisorbed and chemisorbed waters refer to water with molecules attached to another substance, that is sorption water. Physisorbed water does not involve chemical reactions on the surface of the substance to which the water molecules are attached, but chemisorbed water does involve chemical reactions. ULI water can trigger chemical processes such as $\mathrm{OH}$-driven oxidation of organics and the covering of carbonates by sulfates (Möhlmann 2005). This form of liquid water is relevant to habitability because microorganisms could survive by utilizing adsorbed water (Rivkina et al. 2000).

Sorption water, either physisorbed or chemisorbed, has been detected at Mars' low and midlatitudes by the Neutron Spectrometer (NS) (Feldman et al. 2004) and the HighEnergy Neutron Detector (HEND) (Mitrofanov et al. 2004). Both instruments are part of the Gamma-Ray Spectrometer onboard the 2001 Mars Odyssey spacecraft. The data collected by these two instruments was used to estimate the water content $a_{m}=M_{\mathrm{H}_{2} \mathrm{O}} / m_{d r y}$ of the top 1-2 $\mathrm{m}$ of the Martian regolith based on measurements of its hydrogen content, where $M_{\mathrm{H}_{2} \mathrm{O}}$ and $m_{d r y}$ refer to the masses of water molecules and dry material. Since at these latitudes liquid water and water ice are unstable (Mellon et al. 2004), besides brines, only sorption water can account for the estimated soil water contents.

Van der Waals forces between mineral surfaces and water ice molecules cause a freezing point depression that allows physisorbed water to be liquid-like at temperatures well below 273.16 K. This freezing point depression is caused by the sandwiching of a layer of ULI water of thickness $d$, between the mineral surface and external layers of ice (Möhlmann 2008). The freezing point depression of this layer of water is

$$
\Delta T=\frac{A T_{m}}{6 \pi \rho_{i c e} q d^{3}},
$$

where $A$ is the Hamaker constant, $\rho_{i c e}$ is the density of ice, $T_{m}=273.16 \mathrm{~K}$ is the freezing temperature of bulk water, and $q=3.33 \times 10^{5} \mathrm{~J} \mathrm{~kg}^{-1}$ is the latent heat of freezing per unit mass. For typical values of $A=10^{-19} \mathrm{~J}$ and $\rho_{\text {ice }}=916.8 \mathrm{~kg} \mathrm{~m}^{-3}$ (Möhlmann 2011b), the freezing point depression is $110 \mathrm{~K}$ for $d=0.35 \mathrm{~nm}$. This thickness corresponds to that of a single monolayer of physisorbed water, and lies within the range where Van der Waals forces are most effective. Thus, liquid-like physisorbed water can be present at temperatures as low as $163 \mathrm{~K}$.

Next we demonstrate that part of the soil water content estimated from measurements by HEND and NS correspond loosely to that of physisorbed water being exchanged diurnally between the atmosphere and the surface. At low and midlatitudes, the measured water content is $\sim 2 \%$ in a layer extending from the surface down to around $0.07-0.2 \mathrm{~m}$ below it, and $\sim 10 \%$ in an underlying layer extending down to $1-2 \mathrm{~m}$ below the surface (Mitrofanov et al. 2004). The depth of the near surface layer corresponds to a soil column of $10-30 \mathrm{~g} / \mathrm{cm}^{2}$ and density $1500 \mathrm{~kg} \mathrm{~m}^{-3}$, while the bottom of the underlying layer corresponds to the penetration depth of the HEND and NS measurements. Next we show that water physisorbed from the atmosphere can account for the amount of water estimated to be present in the upper $0.07-0.2 \mathrm{~m}$ of the regolith, but could not account for the water estimated to be present deeper in the soil. Assuming a typical atmospheric water content of $10 \mathrm{pr} \mu \mathrm{m}$ and a soil with typical specific surface of $S_{M}=5.4 \times 10^{4} \mathrm{~m}^{2} \mathrm{~kg}^{-1}$, the thickness of the wetted soil in direct adsorptive diurnal exchange with the atmosphere would be of the order of a millimeter 
(Möhlmann 2004). The number of monolayers of physisorbed water that can form during a diurnal cycle is then

$$
n=\left(\frac{(A / 6 \pi) \delta^{-3}}{\left(\rho_{\mathrm{H}_{2} \mathrm{O}} / m_{\mathrm{H}_{2} \mathrm{O}}\right) k T\left|\ln \left(a_{w}\right)\right|}\right)^{1 / 3},
$$

where $\delta=3.5 \times 10^{-10} \mathrm{~m}$ is the thickness of a monolayer of physisorbed water, $\rho_{\mathrm{H}_{2} \mathrm{O}}=$ $10^{3} \mathrm{~kg} \mathrm{~m}^{-3}$ is the density of liquid water, $m_{\mathrm{H}_{2} \mathrm{O}}=3 \times 10^{-26} \mathrm{~kg}$ is the mass of a water molecule, and $k=1.38 \times 10^{-23} \mathrm{~m}^{2} \mathrm{~kg} \mathrm{~s}^{-2} \mathrm{~K}^{-1}$ is the Boltzmann constant. Taking the Hamaker constant to be $A=10^{-19} \mathrm{~J}$, it follows from Eq. (2) that the maximum number of monolayers that form at night, when the temperature is low and the relative humidity is high, can be as large as $n=5$ for typical nighttime conditions ( $T=180 \mathrm{~K}$ and $\left.a_{w}=0.99\right)$. The minimum number of monolayers that form during the day, when the temperature is high and the humidity is low, can be as low as $n=1$ for typical daytime conditions ( $T=250 \mathrm{~K}$ and $a_{w}=0.15$ ). Since the soil water content can be expressed as a function of the number of monolayers as

$$
a_{m}=S_{M} \rho_{\mathrm{H}_{2} \mathrm{O}} n \delta,
$$

calculations suggest that the possible range of monolayers can account for the $a_{m} \sim 2 \%$ measured in the top $0.07-0.2 \mathrm{~m}$ of the soil. In fact, it follows from Eq. (3) that one monolayer $(n=1)$ around the particles of the regolith accounts for $a_{m}=2 \%$ of the soil water content, while $n=5$ accounts for $a_{m}=10 \%$ of the soil water content. Thus, the $2 \%$ value estimated for the top regolith using HEND and NS measurements is consistent with the values calculated assuming that the water is physisorbed.

However, Möhlmann (2005) shows that no more than two monolayers of water adsorbed from the atmosphere can form at depths greater than $0.2 \mathrm{~m}$ in the current climate. Based on Eq. (3), two monolayers fails to explain the soil water content value $a_{m} \sim 10 \%$ inferred from measurements at those depths. Therefore, liquid brines, or perhaps either physisorbed or chemisorbed water formed in an ancient and wetter climate must account for it. Möhlmann (2004) shows that physisorbed water, and in particular chemisorbed water, has stronger bond energies than liquid water or ice, and could survive at those depths over geological timescales. This supports the water sorption idea.

\subsubsection{Subsurface Melt Water}

Water ice can melt in the upper subsurface of snow/ice packs despite the surface being frozen at temperatures below $273.16 \mathrm{~K}$. This melting is caused by a solid-state greenhouse effect (Kaufmann et al. 2006). Snow-ice packs are optically thin in the visible spectral band and opaque in the thermal infrared band. Thus, incoming solar irradiance is efficiently transmitted across the snow/ice surface and absorbed in their subsurface. The warming of the subsurface caused by the absorption of solar radiation can be counteracted only by heat conduction and by the slow sublimation of water molecules removed by diffusion. The remaining net energy can be used to melt water. At the surface, water is less likely to melt because sublimation, the emission of IR radiation and convection also remove heat.

Subsurface melt water has not been detected unambiguously on Mars yet. However, as explained in Sect. 3 there are speculations that flow-like features observed in the polar region are caused by subsurface melt water (Möhlmann 2010).

The melting of ice in the subsurface is governed by the heat conduction equation

$$
\rho_{\text {ice }} c_{i c e} \frac{\partial T(z, t)}{\partial t}-\frac{\partial}{\partial z}\left(\lambda_{i c e} \frac{\partial T(z, t)}{\partial z}\right)=-\frac{d E(z, t)}{d z},
$$


where $c_{i c e}$ and $\lambda_{\text {ice }}$ are the heat capacity and thermal conductivity of water ice. The term on the right is the heat source, and can be obtained from

$$
E(z, t)=E_{0}\left(1-\alpha_{i c e}\right) e^{-z / L_{a b s}},
$$

where $E(z, t)$ is the solar irradiance reaching a depth $z$ of a partially translucent layer of snow or ice, $E_{o}$ is the solar irradiance reaching the surface, $\alpha_{i c e}$ is the surface albedo, and $L_{a b s}$ is the absorption depth (flux extinction depth). The cooling by sublimation balancing the diffusion of water molecules is not included in Eq. (4) because this effect is inhibited by the refreezing of water molecules at colder areas nearby (Grün et al. 1993). The latent heat term has not been considered either, and thus the temperatures predicted by Eq. (4) are valid only up to $273.16 \mathrm{~K}$.

Two boundary conditions are necessary for solving Eq. (4). One plausible boundary condition is to set the heat flow to zero at the bottom of the snow/ice layer being considered. The other boundary condition is set at the surface. Assuming heat balance between the snow/ice surface and the atmosphere, we get another plausible boundary condition

$$
\varepsilon \sigma\left(T_{0}(t)^{4}-T_{s k y}^{4}\right)+H Z(t)+A L-\lambda_{i c e} \frac{\partial T(z=0, t)}{\partial z}=E_{0}\left(1-\alpha_{i c e}\right),
$$

where $T_{0}(t)$ is the surface temperature, $\varepsilon$ is the IR-emissivity, $\sigma=5.67051 \times$ $10^{-8} \mathrm{~W} \mathrm{~m}^{-2} \mathrm{~K}^{-4}$ is the Boltzmann constant, $T_{\text {sky }}$ is the IR-sky temperature, $H=8.4675 \times$ $10^{-20} \mathrm{~J}$ is the enthalpy of sublimation per water molecule and $Z$ is the number of sublimation-released water molecules into the atmosphere per square meter and per second. Eq. (6) states that, at equilibrium, the solar heating is balanced by radiative, evaporative, convective $(A L)$ and conductive loses of energy. Hecht (2002) studies each term of Eq. (6) in detail and shows that, unlike on Earth, on Mars atmospheric pressure is as important as atmospheric temperature in determining the thermal balance at the surface-atmosphere interface. He argues that because only a few molecules contribute to heat transfer between the surface and the rarified air near the surface of Mars, evaporative cooling is much larger than sensible heat and therefore is the largest of these two terms of the heat exchange with the atmosphere.

Möhlmann (2010) shows via Eqs. (4), (5), and (6) that melt water can form in the shallow subsurface. Specifically, he shows that subsurface temperatures can exceed the melting point temperature at depths ranging from 5 to $10 \mathrm{~cm}$ when typical values $\rho_{\text {ice }}=600 \mathrm{~kg} \mathrm{~m}^{-3}$, $c_{\text {ice }}=1960 \mathrm{~J} \mathrm{~kg}^{-1} \mathrm{~K}^{-1}, \lambda_{\text {ice }}=0.019-0.17 \mathrm{~W} \mathrm{~m}^{-1} \mathrm{~K}^{-1}, \alpha_{\text {ice }}=0.2-0.8, L_{a b s}=10 \mathrm{~cm}, \varepsilon=$ $0.96, T_{\text {sky }}=130 \mathrm{~K}, A L=20 \mathrm{~W} \mathrm{~m}^{-2}$, and $Z$ given in Table 2 of Taylor et al. (2006) are considered.

Having temperatures above the freezing point value is a necessary condition for ice to melt. Additionally, specific energy large enough to balance the latent heat of fusion $\left(q=3.335 \times 10^{5} \mathrm{~J} \mathrm{~kg}^{-1}\right)$ must be supplied for the phase transition to occur. For melting of a layer of water ice of height $h$, at a depth $z$, and in a time interval $\Delta t$, subject to an amount of insolation $E(z, t)$ given by Eq. (5), the relationship $\rho_{\text {ice }} q h=E_{0}\left(1-\alpha_{i c e}\right) \Delta t$ must be satisfied for ice to melt. The irradiance reaching the surface is typically around $E_{0}=300 \mathrm{~W} \mathrm{~m}^{-2}$ at polar latitudes $\left(-72^{\circ}\right)$ during spring $\left(L_{s}=210^{\circ}\right)$. Thus, under these conditions, even in a bright surface of $\alpha=0.8$ a layer of liquid water of thickness of the order of $h=1 \mathrm{~mm}$ can form in $\Delta t=90 \mathrm{~min}$, at $z=5 \mathrm{~cm}$ below the surface.

The preferred locations for subsurface water ice to melt are the polar regions because in these regions surface ice and snow can be stable in the current climate (Mellon et al. 2004). In the polar summer, melt water can persist close to the surface even at night (Möhlmann 2011b). 


\subsubsection{Groundwater}

Aquifers as shallow as $\sim 100 \mathrm{~m}$ below the surface might exist on Mars (Goldspiel and Squyres 2011). Possible combinations of the typical geothermal heat flux with a thick, lowconductivity and sufficiently permeable regolith, result in the melting of ice this shallow, allowing the formation of aquifers (Mellon and Phillips 2001). This is extremely important because aquifers could support biological activity (Gaidos 2001). Groundwater has not been detected unambiguously on Mars yet, but rheological features such as gullies have been hypothesized to form by the discharge of shallow aquifers (Malin and Edgett 2000). These features and their possible formation mechanism are discussed in Sect. 3.

The formation of groundwater is described simply by the heat equation applied to the subsurface, coupled with an equation describing the growth of ice in an aquifer, but orbitally induced variations in the mean annual surface temperature are necessary to estimate the discharge of groundwater onto the surface. These orbital variations can cause freeze/thaw cycles in aquifers, eventually generating pressures high enough to fracture ice-cemented ground and allow water to escape to the surface (Mellon and Phillips 2001).

The preferred location for groundwater to form is at midlatitudes in both hemispheres. Surface temperatures are regularly higher (Forget et al. 1999) and ground ice is more prevalent at midlatitudes than near the equator (Heldmann et al. 2007). Groundwater formation at these latitudes is a possible explanation for the larger occurrence of gullies between $32^{\circ}$ and $48^{\circ} \mathrm{S}$ than at other latitudes. The presence of salts in the soil would relax the necessary conditions for the formation of groundwater (Goldspiel and Squyres 2011), allowing underground reservoirs of salty groundwater to form in larger portions of the planet.

\subsubsection{Liquid Brines}

Liquid brines are concentrated aqueous saline solutions. Salts in contact with water reduce both the freezing point temperature and the saturation water vapor pressure. Salts absorb water when exposed to moist air and form liquid aqueous solutions when the relative humidity is above a threshold value known as the deliquescence relative humidity, $D R H$ (e.g., Seinfeld and Pandis 2006). However, the solutions usually remain liquid until the relative humidity falls below a much lower value known as the efflorescence relative humidity, $E R H$ (e.g., Seinfeld and Pandis 2006). Liquid brines can form at temperatures well below $273 \mathrm{~K}$ and in extremely dry environments. For example the saturation vapor pressure at the triple point of water is approximately $611 \mathrm{~Pa}$, but the saturation pressure of liquid brines at $210 \mathrm{~K}$ can be lower than 0.1-0.2 $\mathrm{Pa}$, of the order of the partial pressure of water vapor on Mars equatorial region (Haberle et al. 2012). The minimum temperature at which the brine of a given salt can be liquid is known as the solution eutectic temperature $T_{e}$, and the salt concentration at this temperature is known as the eutectic concentration $\chi_{\text {eut }}$. As indicated in Table 1, various brines that might exist on Mars have eutectic temperature lower than $210 \mathrm{~K}$.

The idea that liquid brines exist on Mars is exciting because many microorganisms thrive in terrestrial brines, particularly in brines found in subglacial environments (Mikucki et al. 2009). Rennó et al. (2009b) showed physical and thermodynamical evidence that liquid brines exist at the Phoenix landing site. Material splashed on a strut of the Phoenix spacecraft during its landing on Mars darkened, grew in proportion to their initial volume as predicted by Raoult's law, and the spheroid that grew most appears to have dripped off as predicted by a stability analysis of droplets of liquid brines (Rennó et al. 2009b). The "smoking gun" that at least one spheroid dripped off and therefore must have been liquid was the fact that it darkened just before disappearing, suggesting complete liquefaction, and that growth was 
Table 1 Eutectic points of salts likely to be present on Mars (Möhlmann and Thomsen 2011). The eutectic temperatures of these salts are exceeded at low and midlatitudes over the entire year, and at polar regions during spring and summer. The threshold relative humidity $D R H$ for these salts to deliquesce is theoretically reached on the surface only poleward of $\pm 60^{\circ}$ and during the spring (Möhlmann 2011a), when the water vapor content of the Martian atmosphere peaks (Smith 2004)

\begin{tabular}{llll}
\hline Salt & $T_{e}(\mathrm{~K})$ & DRH $(\%)$ & 巫 $(\mathrm{wt} \%)$ \\
\hline $\mathrm{H}_{3} \mathrm{PO}_{4}$ & 203 & 41 & 60 \\
$\mathrm{LiCl}$ & 206 & 48 & 24 \\
$\mathrm{Mg}\left(\mathrm{ClO}_{4}\right)_{2}$ & 206 & 53 & 44 \\
$\mathrm{KOH}$ & 210 & 50 & 32 \\
$\mathrm{AlCl}_{3}$ & 214 & 53 & 25 \\
$\mathrm{ZnCl}_{2}$ & 221 & 58 & 52 \\
$\mathrm{CaCl}_{2}$ & 226 & 60 & 30 \\
$\mathrm{NiCl}_{2}$ & 230 & 64 & 30 \\
$\mathrm{NaClO}_{4}$ & 236 & 52 & 68 \\
\hline
\end{tabular}

subsequently suppressed only on its original location, suggesting that salts splashed there during landing were removed (Rennó et al. 2009b).

In addition to the evidence for liquid brines in areas disturbed by the Phoenix lander, Rennó et al. (2009b) showed evidence that soft ice found in trenches excavated by the Phoenix's robotic arm was frozen brine. This is significant because it suggests that liquid brines may also exist in undisturbed areas of Mars. The idea that Phoenix found liquid brines is supported by the detection of perchlorate salts (in particular, $\mathrm{Mg}\left(\mathrm{ClO}_{4}\right)_{2}$ and $\mathrm{NaClO}_{4}$ ) at its landing site (Hecht et al. 2009). These salts have eutectic temperatures between about $205 \mathrm{~K}$ and $235 \mathrm{~K}$ and deliquesce at the environmental conditions of the Phoenix landing site (Chevrier et al. 2009; Zorzano et al. 2009).

There is no question that theoretically liquid brines can form at the surface and in the shallow and deep subsurface of Mars, even in the present climate. Indeed, liquid brines can form by deliquescence at the surface and in the shallow subsurface $(\leq 1 \mathrm{~m})$. At the shallow subsurface it can also form by direct contact of salts with physisorbed water and melt water. In the deep subsurface $(\geq 100 \mathrm{~m}$ ) it can form by direct contact of salts with aquifers.

The phase diagrams of aqueous solutions are usually constructed by plotting temperature as a function of salt concentration, or temperature as a function of relative humidity $(R H)$. The two versions are equivalent because the salt concentration depends on both the temperature and the water vapor partial pressure, and therefore the relative humidity. As an example, Fig. 2 shows the phase diagram of $\mathrm{Mg}\left(\mathrm{ClO}_{4}\right)_{2}$, a salt found in large quantities at the Phoenix landing site. It is shown that salts deliquesce when the $R H$ exceeds the deliquescence relative humidity $(D R H)$. However, the reverse process (efflorescence, crystallization of a salt solution), generally occurs at lower relative humidity (open circles in Fig. 2). Thus, phase diagrams show a hysteresis effect, which relaxes the conditions for brines to exist, and thus extends their "lifetime" in the liquid state. Gough et al. (2011) showed experimentally that, under the environmental conditions of the Phoenix landing site, $\operatorname{Mg}\left(\mathrm{ClO}_{4}\right)_{2}$ brines could have formed on the strut of the Phoenix lander.

Polar latitudes are the preferred locations for liquid brines to form, although they might also form in low and midlatitudes. Three conditions must be met for liquid brines to form: (i) the presence of salts, (ii) temperatures above $T_{e}$, and (iii) relative humidity above the deliquescence value $R H>D R H$. The presence of liquid water-either physisorbed, melt water, 


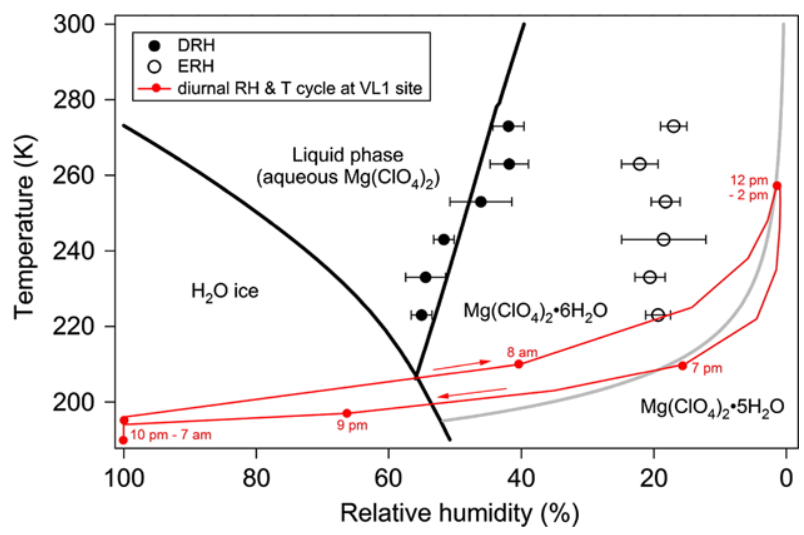

Fig. 2 Phase diagram of $\mathrm{Mg}\left(\mathrm{ClO}_{4}\right)_{2}$ as a function of temperature and relative humidity. The solid curves are based on theoretical calculations, while the symbols represent values determined experimentally. The eutectic point is at $206 \mathrm{~K}$ and $44 \mathrm{wt} \%$. The gray curve indicates the transition between the pentahydrate and hexahydrate hydration states. The deliquescence relative humidity (closed circles) increases with decreases in temperature from $42 \%$ at $273 \mathrm{~K}$ to $54 \%$ at $223 \mathrm{~K}$. However, the efflorescence relative humidity (open circles) is constant at around $\sim 19.3 \%$ and therefore is independent of temperature. Gough et al. (2011) show that, based on the diagrams above and our knowledge of the environmental conditions at the Phoenix landing site, the droplets shown in Fig. 3 are likely brines of $\mathrm{Mg}\left(\mathrm{ClO}_{4}\right)_{2}$. The red lines represent the variations of temperature and relative humidity during a diurnal cycle at the Viking 1 landing site. From Gough et al. (2011). Reprinted with permission from Elsevier

or groundwater - can provide moisture to cause the humidity to increase above the deliquescence value at the surface and in the subsurface in salt particles near them or in direct contact with them. We show next that the three conditions for the formation of brines described above are most likely to be met simultaneously at Mars polar regions. First, perchlorates, chlorides, sulfates, and carbonates have been detected scattered around many areas of Mars, extending from the polar to the equatorial regions (Möhlmann and Thomsen 2011). Second, the eutectic temperatures of many salts involving these substances and likely to be present on Mars (see Table 1) are exceeded at low and midlatitudes over the entire year, and at polar latitudes during spring and summer. Third, the threshold $D R H$ for the salts listed in Table 1 to deliquesce is theoretically reached on the surface only poleward of $\pm 60^{\circ}$ and only during the spring (Möhlmann 2011a), when the water vapor content of the Martian atmosphere peaks (Smith 2004). The water vapor content is the most limiting factor, and this explains why the north and south polar regions are the most favorable for the formation of brines at the surface. However, ULI water and groundwater could form in the subsurface at low and midlatitudes. The direct contact of ULI water and groundwater with salts could provide the moisture to cause the humidity increase above the $D R H$ value even in midlatitude and equatorial regions.

\section{Observational Evidence for Liquid Brines on Mars}

In this section, we show evidence that liquid brines currently exist temporarily on the surface and in the subsurface of Mars. As discussed in previous sections, for water substance to exist as liquid on the surface and in the subsurface of Mars in the current climate, it must be in the form of ULI water, melt water, liquid brines or groundwater. Landforms suggesting water activity in the distant past such as fluid-eroded channels, valleys networks, or glacial and 
Table 2 List of possible wet features observed on Mars north and south polar regions. DDS stands for dune dark spots and FLF for flow-like features

\begin{tabular}{lll}
\hline & Spheroids \& Soft ice & DDS \& FLF \\
\hline Latitude & $68.22^{\circ} \mathrm{N}$ (Phoenix & $\geq 54^{\circ} \mathrm{S}$ \\
& landing site) & $\geq 77^{\circ} \mathrm{N}$ \\
Formation time & Late Spring & Late Winter (Spring growth) \\
Terrain & Polar plains & Polar dunes \\
Orientation & - & No pattern \\
"Wet" mechanism & Brines grown by & - Liquid Brines \\
& deliquescence & - ULI water \\
"Dry" mechanism & & - Subsurface melt water \\
\hline
\end{tabular}

Table 3 Same as Table 2, but in low and midlatitudes. RSL stands for recurring slope lineae

\begin{tabular}{|c|c|c|c|}
\hline & Gullies & RSL & Slope streaks \\
\hline Latitude & $\begin{array}{l}\text { Scattered (Mostly at } 30^{\circ}- \\
45^{\circ} \mathrm{S} \text { ) }\end{array}$ & $32^{\circ}-48^{\circ} \mathrm{S}$ & $\leq 40^{\circ}$ (Both hemispheres) \\
\hline Formation time & Winter (Not certain) & Spring & No pattern \\
\hline Terrain & No pattern & $\begin{array}{l}\text { - Dark regions } \\
\text { - Moderate thermal inertia } \\
\text { - Low dust index }\end{array}$ & $\begin{array}{l}\text { - High albedo } \\
\text { - Low thermal inertia } \\
\text { - High dust index }\end{array}$ \\
\hline Orientation & No pattern & Equator-facing slopes & No pattern \\
\hline "Wet" mechanism & $\begin{array}{l}\text { - Near-surface ice melting } \\
\text { - Snowpacks melting } \\
\text { - Groundwater discharge }\end{array}$ & $\begin{array}{l}\text { Briny flows from: } \\
\text { - Groundwater discharge } \\
\text { - Deliquescence }\end{array}$ & $\begin{array}{l}\text { Chloride and perchlorate } \\
\text { brines flow }\end{array}$ \\
\hline "Dry" mechanism & $\begin{array}{l}\text { - Lubricated } \mathrm{CO}_{2} \text { gas } \\
\text { - Granular frosted } \mathrm{CO}_{2} \\
\text { - Eolian material } \\
\text { (dust\&silt) }\end{array}$ & Not given & Dust avalanches \\
\hline
\end{tabular}

periglacial surface features, are not reviewed in this article. The reader is referred to Masson et al. (2001) for an excellent review of this subject.

The various wet-like features observed on Mars can be classified based on the latitude zones in which they form. We refer to the spheroids observed on a strut of the Phoenix lander, the soft ice found in trenches dug by Phoenix, and the dark spots and the flow-like features (FLF) observed in polar dunes as brine-like features occurring in the polar region (Table 2). Gullies, Recurring Slope Lineae (RSL), and slope streaks occurring in low and midlatitudes complete the set of possible wet features observed on Mars (Table 3).

Next we describe the features summarized above, study their formation, and discuss the "wet" and "dry" mechanisms that have been proposed to explain them.

\subsection{Polar Regions}

\subsubsection{Spheroids and Soft Ice at the Phoenix Landing Site}

Rennó et al. (2009b) showed observational and theoretical evidence for liquid brines both in disturbed and in undisturbed areas at the Phoenix landing site. The impingement of the 

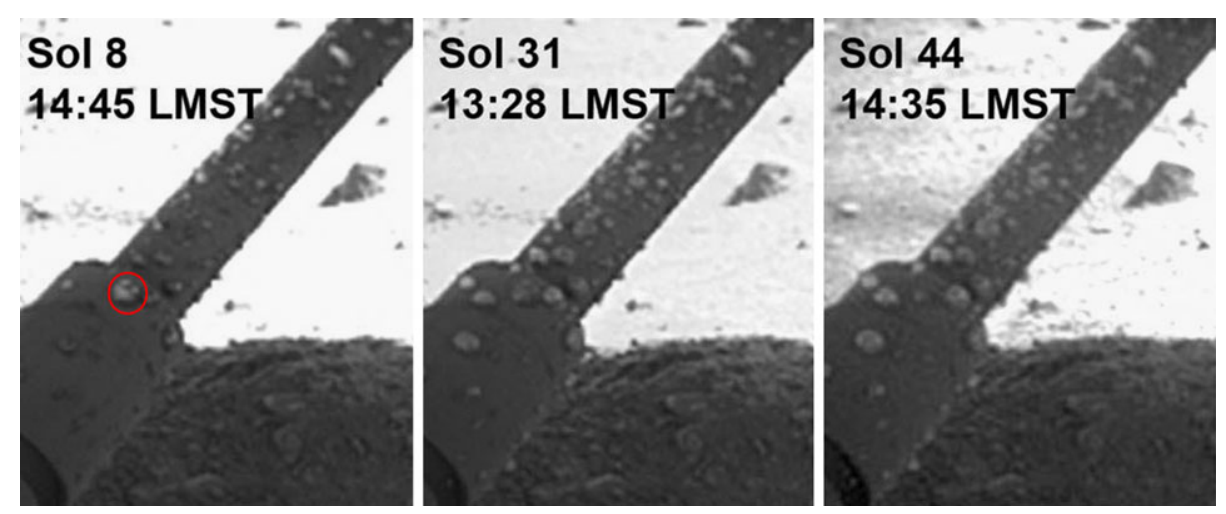

Fig. 3 Phoenix Robotic Arm Camera (Keller et al. 2008) images of a strut on Sols 8, 31, and 44. The "smoking gun" that spheroids like that encircled in red must have been liquid, is the fact that they grew in proportion to their initial volume as predict by Raoult's Law, that they darkened just before disappearing (likely dripping off as predicted by stability analysis), and that growth was subsequently suppressed only over the material that appear to have dripped off, carrying the deliquescent salts with them. The thinner part of the strut is $3.05 \mathrm{~cm}$ in diameter. From Rennó et al. (2009b). Reproduced by permission of the American Geophysical Union

Phoenix thruster plumes on the surface of Mars removed topsoil (Mehta et al. 2011), and splashed soil mixed with melted ice into struts of its leg. Some of the material splashed adhered to the struts. There is evidence that the material splashed on the struts grew by deliquescence as predicted by Raoult's law and formed spheroids, as shown in Fig. 3. In undisturbed areas, soft water ice was found in a trench and removed without effort (Fig. 4). This is expected from a soft frozen brine but not from pure water ice (Rennó et al. 2009a). Mellon et al. (2009) suggested that the soft ice found in this trench could be soft because it was a low density pure water ice. However, this pure water ice would not leave whitish material behind after sublimating as observed in the Phoenix trench. Rennó et al. (2009b) suggested that the white material was salt crystals left behind after the sublimation of the brine. The discovery of perchlorate salts at the Phoenix landing site (Hecht et al. 2009) support the idea that brines were present in both disturbed and undisturbed areas.

Rennó et al. (2009b) reported multiple physical and thermodynamical evidence that the spheroids that formed on struts of the Phoenix landing leg were liquid brines that grew via deliquescence. The physical evidence that they were liquid brines is that spheroids grew in proportion to their initial volume, dripped, and merged, as shown in Fig. 3. Darkening is expectable from liquefaction (Perovich 1994) because liquid water scatters less light than ice. The thermodynamic evidence that the spheroids grew by deliquescence is the fact that their temperature was above the eutectic temperature of salts discovered by Phoenix (Möhlmann and Thomsen 2011), the atmospheric humidity was above the deliquescence relative humidity value for some of these salts (Möhlmann 2011a), and that the spheroids disappeared toward the end of the mission when the temperature decreased below the eutectic value, probably causing them to freeze and sublimate. Finally, laboratory experiments with perchlorate salts under the environmental conditions of the Phoenix landing site support the idea that perchlorate salts grow by deliquescence there (Gough et al. 2011; Chevrier et al. 2009; Zorzano et al. 2009).

Alternative explanations for the formation of the Phoenix spheroids are that they were either ice particles nucleated by the dark material splashed on the strut, or that they grew by 
Fig. 4 Image of the first trench dug by the Phoenix robotic arm taken by the Surface Stereo Imager (SSI) on Sol 19. Ice was exposed and removed with little effort, suggesting that it was either saline ice or layered ice formed in the presence of brines (much softer than freshwater ice). Ice exposed in a second trench was extremely hard and could be removed only with great effort and the use of a special drill, suggesting that it was not soft frozen brine. From Rennó et al. (2009b). Reproduced by permission of American Geophysical Union

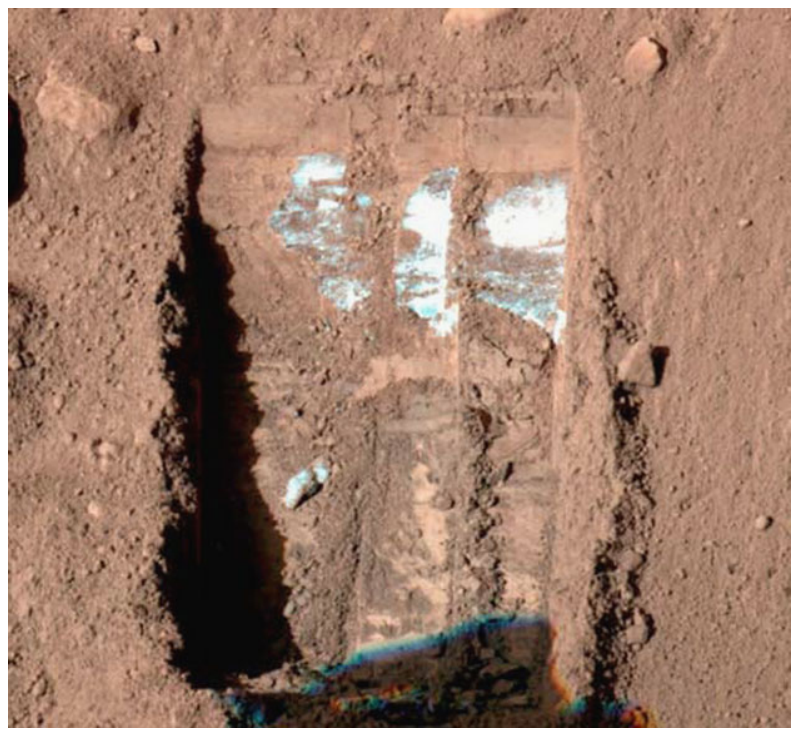

deliquescence, but on contamination products of the thruster engines. Rennó et al. (2009b) show that these are unlikely explanations.

\subsubsection{Dune Dark Spots and Flow-like Features}

Dark spots are distinctly dark albedo features that form on polar dunes, both in the southern and northern hemisphere. FLF emanate from some dark spots located on dune ridges and flow downward. Both dark spots and FLF form in late winter, before the $\mathrm{CO}_{2}$ ice cover sublimates. The widely accepted mechanism for the formation of dark spots and FLF is "gas venting" from the shallow subsurface (Kieffer 2007). This mechanism does not involve liquid water of any type. The proposed mechanism hypothesizes that solar radiation is efficiently transmitted through the translucent $\mathrm{CO}_{2}$ ice layer (Hansen 1999), and is absorbed at the soil-ice interface. Then, the $\mathrm{CO}_{2}$ ice sublimates creating high pressure pockets of $\mathrm{CO}_{2}$ gas at the interface of the ice layer with the dusty soil. Eventually the pressure becomes sufficiently high to break the ice layer and eject $\mathrm{CO}_{2}$ gas and loose material into the Martian air.

There is mounting evidence that while dark spots and FLF form by "dry" gas venting, liquid brines form temporarily on them. Next we describe dark spots and FLF in both the north and south polar regions, explain the proposed "wet" mechanisms associated with their temporal evolution, and describe the alternative "dry" explanations for their temporal evolution.

South Polar Region Two types of dark spots have been observed on southern polar $\left(|\phi|>54^{\circ}\right)$ dunes: large dark spots, typically $>20 \mathrm{~m}$ in diameter, which form on flat surfaces between dunes, and smaller dark spots that form on dune ridges (Kereszturi et al. 2011). FLF 2-10 m wide may emanate downward on $5^{\circ}-20^{\circ}$ steep slopes from the smaller dark spots.

Martinez et al. (2012) give thermodynamical evidence for the formation of liquid brine on large dark spots (Fig. 5). They present a comprehensive methodology to remove atmospheric effects from High Resolution Imaging Science Experiment (HiRISE) data in order 

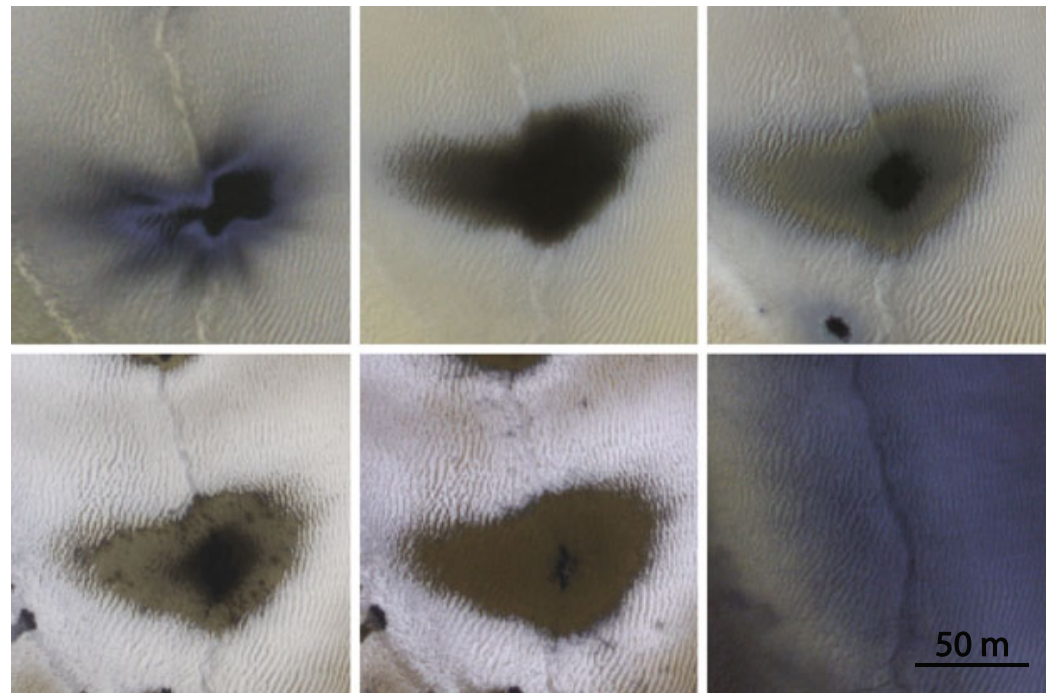

Fig. 5 Sequence of color HiRISE images PSP-002397-1080, PSP-002885-1080, PSP-003175-1080, PSP-003742-1080, PSP-003953-1080, PSP-005298-1080 of Richardson Crater $\left(72.4^{\circ} \mathrm{S}, 179.6^{\circ} \mathrm{E}\right)$ taken at solar longitudes of $175.2^{\circ}, 197^{\circ}, 210.6^{\circ}, 238.1^{\circ}, 248.5^{\circ}$, and $313^{\circ}$. The first image shows the formation of a large dark spot. The formation process is consistent with the ejection of $\mathrm{CO}_{2}$ gas and accompanying granular material up to a distance of about $50 \mathrm{~m}$, as predicted by the gas venting model (Kieffer 2007). Martinez et al. (2012) give thermodynamical evidence that after dark spots form, liquid brine forms on the dark material ejected by them once the solar longitudes reach the range $197^{\circ}-210.6^{\circ}$ (second, third, and fourth figures)

to calculate the albedo of the Martian surface. They use this methodology to study the time evolution of the surface albedo of large dark spots. They hypothesize that an unexpected decrease and subsequent increase in albedo while the surface temperature rises continuously is caused by brine formation and their subsequent freezing. Alternative explanations involving dry processes, such as a second ejection of dark material or dust deposition, could also cause the observed behavior. However, Martinez et al. (2012) show that these explanations are unlikely.

Kereszturi et al. (2009) suggest that ULI water may cause the growth of FLF shown in Fig. 6. Supporting this idea, Möhlmann and Kereszturi (2010) argue that ULI water accumulates at the bottom of a translucent water-ice layer on top of a dark surface, and drive FLF downward. They suggest that the formation of brines must follow from the presence of ULI water in contact with salt particles and develop a numerical model to calculate the growth of FLF. They show that growth at rates as large as $1.4 \mathrm{~m} / \mathrm{sol}$ are consistent with the flow of liquid brines at the soil below an ice layer at the surface. Möhlmann (2010) suggests that subsurface melt water could also explain the growth of FLF. He develops a model to calculate the subsurface temperature below a layer of water ice/snow, and shows that the subsurface temperature can exceed $273.16 \mathrm{~K}$.

North Polar Region Dune dark spots can also be found in areas poleward of $77^{\circ} \mathrm{N}$. Large dark spots, typically 4-25 $\mathrm{m}$ in diameter, form near the top of steep slopes, and smaller dark spots $\leq 4 \mathrm{~m}$ in diameter, form on the top of dunes and on the flat surfaces between dunes (Kereszturi et al. 2010). FLF about 25-100 $\mathrm{m}$ long and 2-10 m wide emanate from steep 

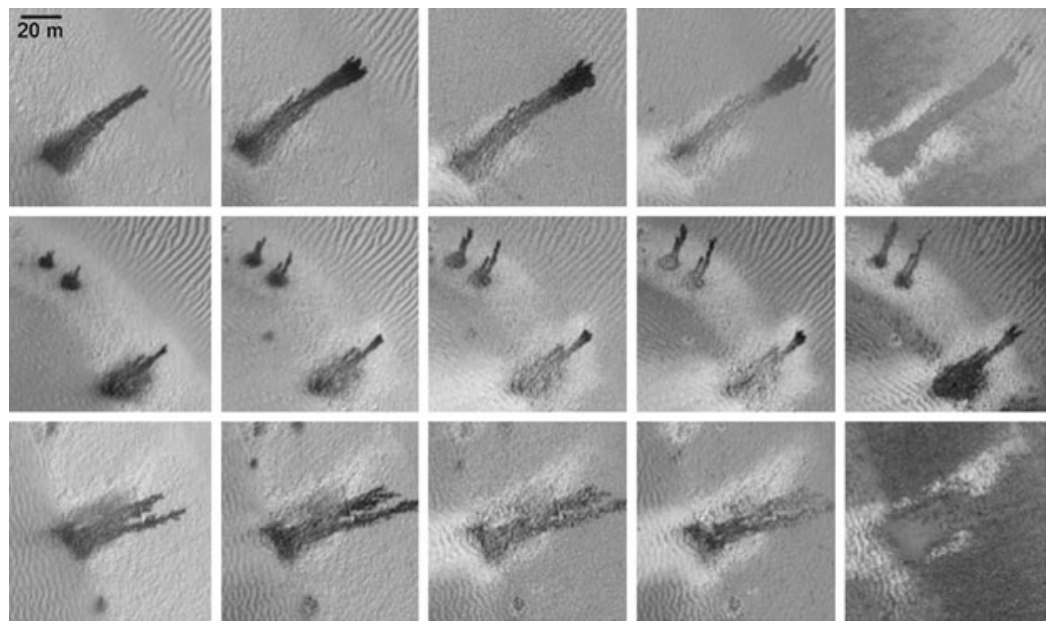

Fig. 6 Sequence of HiRISE images PSP-003175-1078, 003386-1080, 003597-1080, 003742-1080, and 003953-1080 of Richardson Crater $\left(72.4^{\circ} \mathrm{S}, 179.6^{\circ} \mathrm{E}\right)$ taken at solar longitudes of $210.6^{\circ}, 220.7^{\circ}, 230.9^{\circ}$, $238.1^{\circ}$, and $248.5^{\circ}$. These images show the evolution of flow-like features on slopes tilted toward the upper right corner of the images. ULI water, brines, and subsurface melt water, acting alone or together, could be responsible for the growth of these features. From Möhlmann and Kereszturi (2010). Reprinted with permission from Elsevier
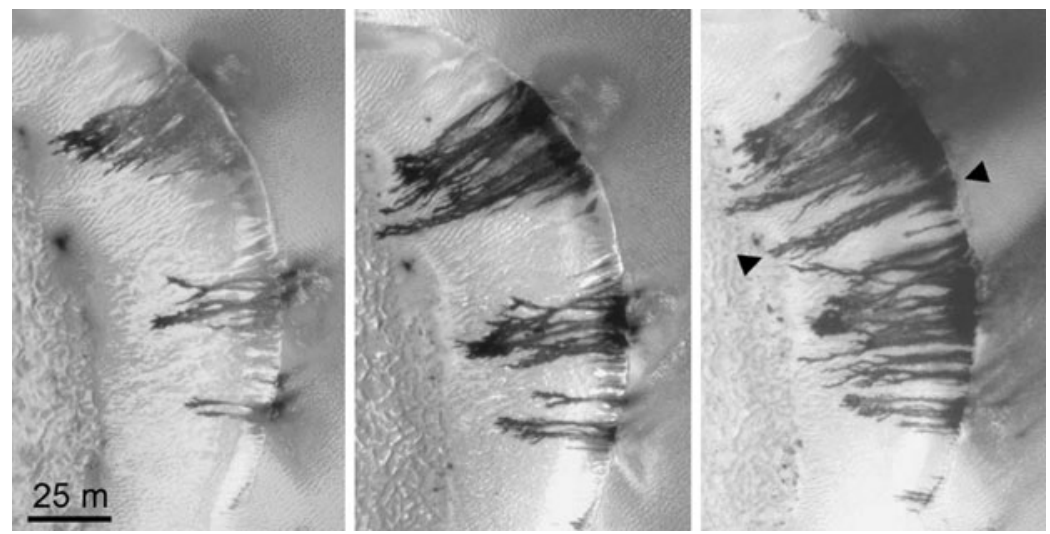

Fig. 7 Sequence of HiRISE images PSP-007468-2575, 007758-2575 and 007903-2575 of northern polar dunes $\left(77.5^{\circ} \mathrm{N}, 300.1^{\circ} \mathrm{E}\right)$ taken at solar longitudes of $38.6^{\circ}, 48.7^{\circ}$, and $63.0^{\circ}$. They show the growth of flow-like features as the season progresses from spring toward summer. The time interval between the images is 22 and 12 Sols. Arrows indicate flow-like features that grow at a rate of about $5 \mathrm{~m} /$ day (60 m in 12 Sols). From Kereszturi et al. (2010). Reprinted with permission from Elsevier

slopes containing large dark spots. The length of FLF grows from spring to summer, on average at rates between 0.3 and $7 \mathrm{~m} /$ day (Fig. 7).

Kereszturi et al. (2010) suggest that FLF are the result of ephemeral water migration in the form of ULI water and liquid brines. Möhlmann (2010) argues that subsurface melt water could also explain the growth of FLF, since in this case liquid brines from salts in contact with subsurface water could also form. As an alternative "dry" mechanism, Hansen et al. (2011) suggest that sand and $\mathrm{CO}_{2}$ ice cascading down the slipfaces of sand dunes produce 
FLF such as those shown in Fig. 7. They argue that brines cannot form under the low surface temperatures $(\sim 180 \mathrm{~K})$ measured by TES and THEMIS at the time of the year that FLF are observed. We show next that the formation of brines can indeed be reconciled with these low surface temperatures.

Reconciling Brine Formation with Low Temperatures Martinez et al. (2012) show that the formation of brines is consistent with the low temperatures measured by TES and THEMIS when they form $(\leq 180 \mathrm{~K})$, if the spatial resolution and optical properties of the translucent $\mathrm{CO}_{2}$ ice layer are considered. The resolution of TES is much coarser than the dimensions of the dark spots and FLF. In addition, TES and THEMIS measurements of the surface temperature are in the thermal infrared band, where $\mathrm{CO}_{2}$ ice is opaque. Since the fractional area covered by dark spots and FLF (composed of dark material above the $\mathrm{CO}_{2}$ ice layer), is much smaller than that covered by $\mathrm{CO}_{2}$ ice in TES and THEMIS pixels, they predominantly measure the low brightness temperature associated with the $\mathrm{CO}_{2}$ ice layer, not the temperature of the dark spots and FLF. As postulated by the gas venting model, shortwave solar radiation can efficiently penetrate the translucent $\mathrm{CO}_{2}$ ice layer. Thus, both the underlying surface and the dark ejecta can reach temperatures much higher than those measured by TES and THEMIS (Martinez et al. 2012). Also, subsurface melt water and ULI water can form in the shallow subsurface at temperatures as low as $180 \mathrm{~K}$ (see Sect. 2). Salts in contact with these types of liquid water could form liquid brines, and thus help explain the evolution of dune dark spots and FLF.

\subsection{Low and Midlatitudes}

\subsubsection{Gullies}

Gullies are complex structures that encompass headward alcoves, distal aprons, and the channels that connect them (Malin and Edgett 2000) (Fig. 8). Typically, gully channels are 1-2 km long, while alcoves are about $100 \mathrm{~m}$ wide. The heads of the gully alcoves usually lie within the upper one-third of the slope into which the gully is eroded, and have depths of less than $200 \mathrm{~m}$ from the overlying ridge.

Gullies are found scattered across nearly the entire surface of Mars, although they predominantly form in the southern hemisphere at latitudes $\geq 27^{\circ}$ on south-facing $20^{\circ}-30^{\circ}$ steep slopes (Malin et al. 2006). Gullies form on any type of terrain, on terrains of any age, and can occur on slopes of any orientation (Treiman 2003). Gullies appear to form during the winter (Dundas et al. 2010), but this is not certain.

The rationale for liquid water to be responsible for the formation of gullies lies in their geomorphic expressions (Malin et al. 2006; Malin and Edgett 2000). Their geomorphology suggests movement of a fluid with properties similar to that of liquid water produced by: (i) melting of near surface ground ice (Costard et al. 2002), (ii) melting of snowpacks at high obliquities (Christensen 2003; Williams et al. 2009), or (iii) groundwater, possibly hosting liquid brines, released from aquifers (Mellon and Phillips 2001; Hartmann 2001; Gaidos 2001).

Three widely accepted alternative dry mechanisms have been proposed to explain the formation of gullies: (i) flow of dry material lubricated by gas released during sublimation of $\mathrm{CO}_{2}$ ice (Hoffman 2002), (ii) flow of $\mathrm{CO}_{2}$ ice triggered by rock falls (Hugenholtz 2008; Dundas et al. 2010), and (iii) dry flows of dust and silt deposited by eolian processes, similar to climax snow avalanches on Earth (Treiman 2003). 
Fig. 8 Subframe of Mars Orbiter Camera image M03-00537 of an area around $54.8^{\circ} \mathrm{S}, 342.5^{\circ} \mathrm{W}$. It shows the landforms that comprise the Martian gullies. The three main geomorphic elements of these features are a theater shaped alcove, triangular aprons that broaden downslope, and one or more major or secondary channels that connect the alcove to the distal apron. From Malin and Edgett (2000). Reprinted with permission from AAAS

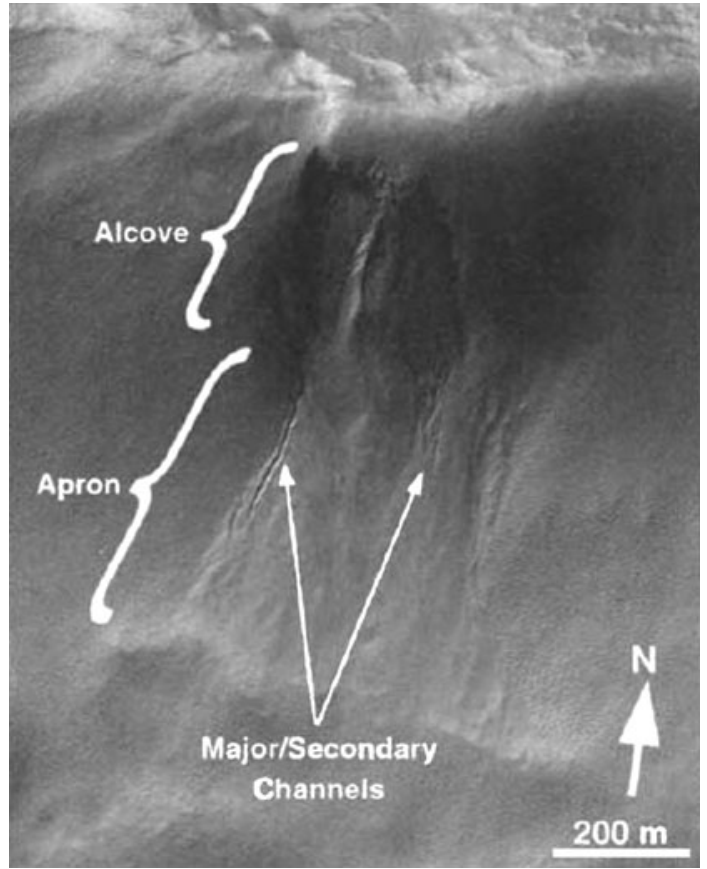

Heldmann et al. (2007) provide a comprehensive review of the strengths and weaknesses of each mechanism proposed to explain the formation of gullies. They suggest that groundwater seepage from deep aquifers is the most likely explanation (Goldspiel and Squyres 2011).

\subsubsection{Recurring Slope Lineae}

RSL are distinct albedo features up to $\sim 40 \%$ darker than their surroundings (McEwen et al. 2011). They form at low and midlatitudes, typically between $32^{\circ} \mathrm{S}$ and $48^{\circ} \mathrm{S}$, on $25^{\circ}-40^{\circ}$ steep equator-facing slopes. RSL form on dark regions with low dust index and with moderate thermal inertia. They are 0.5 to $5 \mathrm{~m}$ wide and can be hundreds of meters long, as shown in Fig. 9. These features are recurrent, forming and growing in late southern spring and summer when peak surface temperatures are between 250 and $300 \mathrm{~K}$, and vanishing during the colder seasons. The growth rate of RSL is as high as $20 \mathrm{~m} /$ day.

McEwen et al. (2011) suggest that brine flows likely cause the formation of RSL. Surface temperatures in the range 250-300 K when RSL form, allow the formation of brines of a variety of salts (see Table 1) via deliquescence if the humidity is high enough to prevent evaporation, or via direct contact with ULI water or groundwater if they are present in the shallow subsurface (melt water is unlikely to form there). Since at these latitudes the relative humidity is unlikely to exceed the DRH values of likely salts candidates (Möhlmann 2011a), brine seep flows either from ULI water or groundwater are the most plausible "wet" explanation for the formation of RSL. In the presence of salts, groundwater discharge requires only modest amounts of water and does not require geothermal heating at the latitudes where RSL form (Goldspiel and Squyres 2011).

MRO's Compact Reconnaissance Imaging Spectrometer (CRISM) (Murchie et al. 2007) has not identified specific absorption features expected from liquid water in RSL. However, 

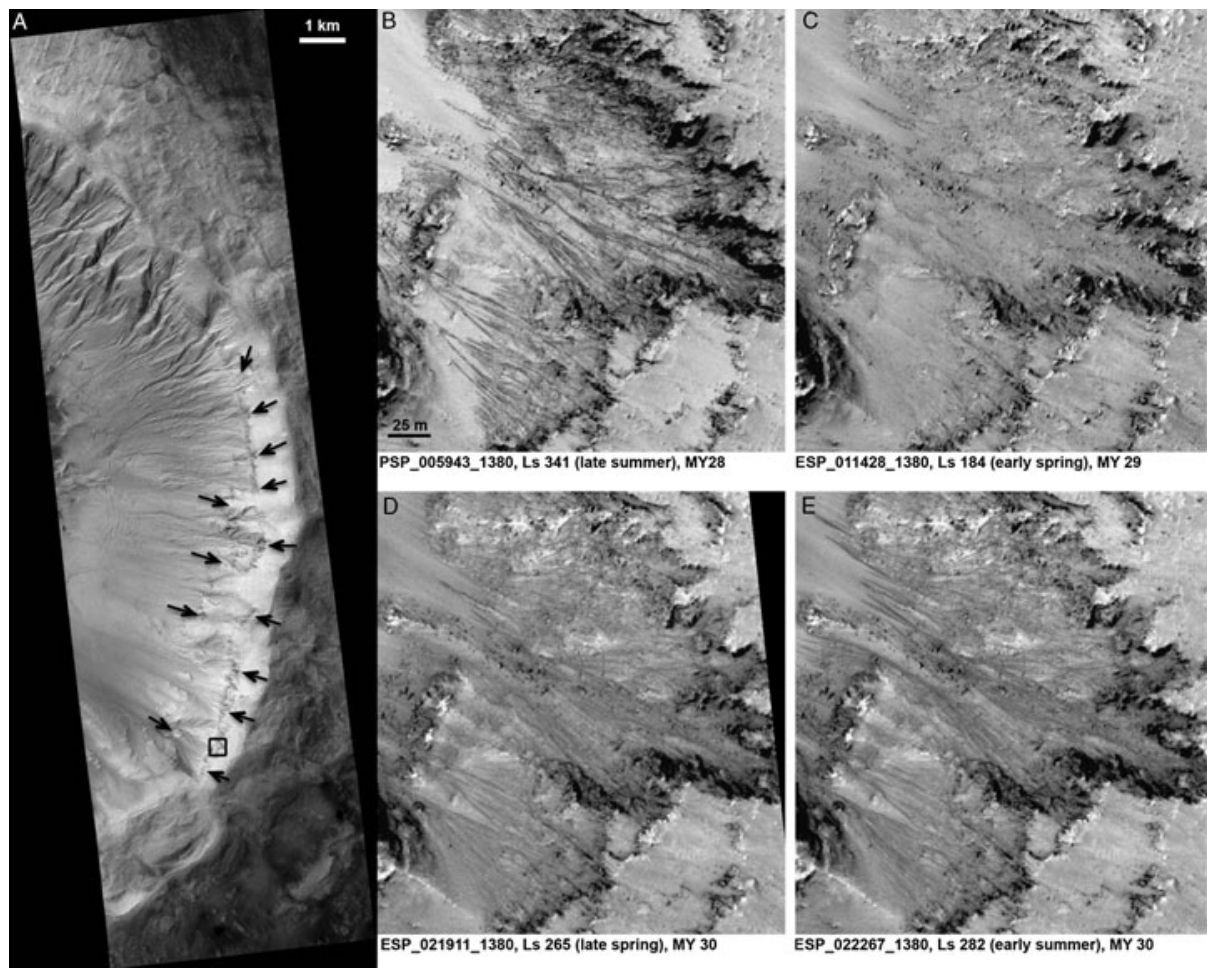

Fig. 9 Impact crater in Newton Basin at $41.6^{\circ} \mathrm{S}, 202.3^{\circ}$ E. Sequence of HiRISE images PSP-005943-1380 (A-B), ESP-011428-1380 (C), ESP-021911-1380 (D), ESP-022267-1380 (E) taken at solar longitudes of $341^{\circ}$ MY 28, $184^{\circ}$ MY 29, $265^{\circ}$ MY 30, and 282 ${ }^{\circ}$ MY 30. (A) Full HiRISE PSP-005943-1380 image with arrows pointing toward concentrations of RSL, and black box displaying orthorectified images showing RSL (dark lines) in the late summer of MY 28 (B), RSL faded by early spring of the MY 29 (C), then RSL gradually darkening while forming again in the spring (D) and summer (E) of MY 30. From McEwen et al. (2011). Reprinted with permission from AAAS

RSL dimensions are below the CRISM resolution (18 m/pixel), and the perchlorates and chlorides expected in various brines on Mars lack distinctive absorption features (Osterloo et al. 2008; Hecht et al. 2009). Alternative dry mechanisms capable of explaining RSL have not been discussed in the literature yet. However, their formation on steep slopes subject to soil avalanches and the high humidity values necessary to prevent brine evaporation at $250-300 \mathrm{~K}$ is a concern.

\subsubsection{Slope Streaks}

Slope streaks are low latitude features that predominantly have albedo darker than that of their surroundings, typically with a difference of up to $10 \%$ (Kreslavsky and Head 2009). They elongate along topographic gradients as steep as $7^{\circ}-25^{\circ}$ of any orientation, and present sharp edges (see Fig. 10). The areas on which slope streaks form typically have low thermal inertia, high albedo, and the spectral signature of fine dust. Slope streaks are as long as $\sim 1000 \mathrm{~m}$ and as wide as $\sim 100 \mathrm{~m}$, while the smallest slope streaks can be meter-scale. The formation of slope streaks is highly inhomogeneous, both in time and in space (King et al. 
Fig. 10 Subframe of MOC image M04-02746 taken at $L_{S}=193.23^{\circ}$ showing four prominent dark slope streaks on slope terrain at $20.90^{\circ} \mathrm{N}$, $329.74^{\circ} \mathrm{W}$. These four dark slope streaks show some characteristics typical of these features, like sharp margins showing no relief, digitate downslope ends, albedo darker than that of their surroundings, and variation of overall albedo between individual features. From Sullivan et al. (2001). Reproduced by permission of American Geophysical Union

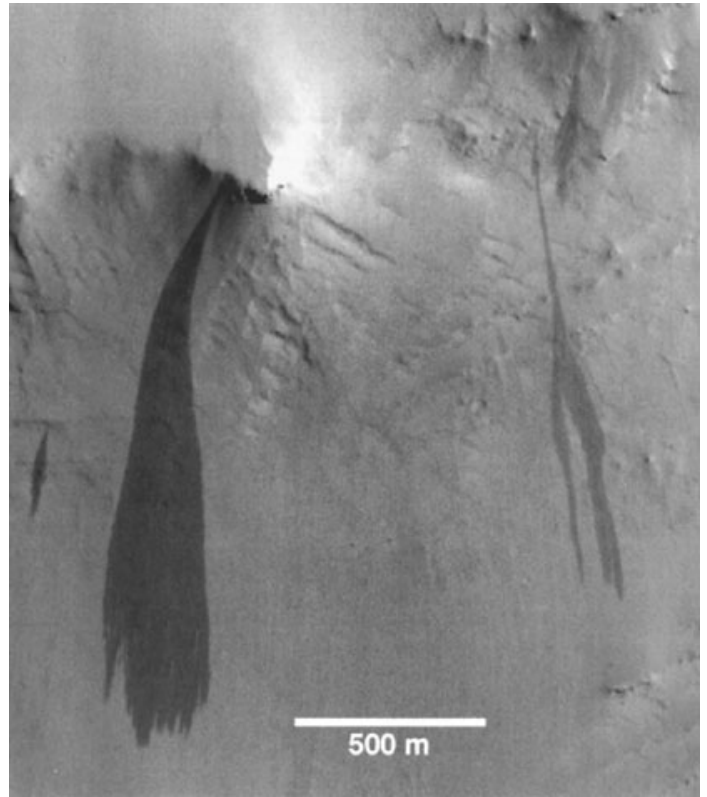

2010). Their fading timescale is as long as decades, and according to CRISM data they show no evidence of hydration.

Kreslavsky and Head (2009) hypothesize that the flow of chloride brines could explain the formation of slope streaks. Chloride and perchlorate brines could form in the upper subsurface during the warm seasons. These brines would percolate downward to depths of decimeters, refreeze, and produce an impermeable layer. Eventually, a run-away percolation front would form on an impermeable layer causing the observed flow. Groundwater discharge has been proposed as an alternative explanation for these features (Ferris et al. 2002).

The most widely accepted explanations for slope streaks involve dry mechanisms. Sullivan et al. (2001) suggest that slope streaks are scars from dust avalanches following overstepping of air fall deposits. King et al. (2010) support this idea by pointing at the lack of seasonality in the formation of slope streaks.

\section{Implications for MSL}

The MSL rover Curiosity landed on Gale Crater, at $4.5^{\circ} \mathrm{S}$ and $137.4^{\circ} \mathrm{E}$ and at an elevation of $-4500 \mathrm{~m}$ (Grotzinger et al. 2012). The surface pressure at the landing site is around $7-8 \mathrm{hPa}$ and a thin layer of frost is expected to form early in the morning, at least during the cold seasons (Haberle et al. 2012). Gale Crater was chosen as a landing site for Curiosity because of its habitability potential. In particular, there is evidence that Gale Crater has salts such as sulfates, had water activity in the past, and have clays (Pelkey et al. 2004; Milliken et al. 2010).

The MSL Curiosity Rover is equipped with optical and analytical instruments (Grotzinger et al. 2012) capable of detecting water and brines in Gale Crater. The DAN instrument is capable of detecting hydrogen which may indicate the presence of water free or bound to minerals (Mitrofanov et al. 2012). The detection of high hydrogen content might suggest the 
existence of water ice or brines in the shallow subsurface. If evidence for brines is found, they could be investigated in detail with analytical instruments such as SAM (Mahaffy et al. 2012), ChemCam (Maurice et al. 2012), CheMin (Blake et al. 2012), APXS (Campbell et al. 2012), as well as with cameras such as MAHLI (Edgett et al. 2012), MastCam and ECAM (Maki et al. 2012). SAM is capable of measuring the amount and composition of volatiles released by a small soil sample as a function of temperature as the sample is heated. Therefore, SAM can provide evidence for the existence of brines in Gale Crater by detecting volatiles and phase transitions.

The discovery of either liquid water or liquid brines would be important because they have significant implications for geochemistry, glaciology, mineralogy, weathering and habitability. Since liquid water is essential for life as we know it, the possible discovery of liquid brines would be extremely important for our understanding of the habitability of Mars. Indeed, many microorganisms thrive in terrestrial brines in favorable ranges of water activity, and in particular in brines found in subglacial environments (Mikucki et al. 2009).

Acknowledgements This research is supported by Award \#09-EXOB09-0050 from the NASA Astrobiology Program: Exobiology and Evolutionary Biology. We thank the anonymous reviewers and the editor for their comments and suggestions.

Open Access This article is distributed under the terms of the Creative Commons Attribution License which permits any use, distribution, and reproduction in any medium, provided the original author(s) and the source are credited.

\section{References}

D. Blake, D. Vaniman, C. Achilles, R. Anderson, D. Bish, T. Bristow, C. Chen, S. Chipera, J. Crisp, D. Des Marais, et al., Characterization and calibration of the CheMin mineralogical instrument on Mars Science Laboratory. Space Sci. Rev., 1-59 (2012)

G.W. Brass, Stability of brines on Mars. Icarus 42(1), 20-28 (1980)

K.L. Bryson, V.F. Chevrier, D.W.G. Sears, R. Ulrich, Stability of ice on Mars and the water vapor diurnal cycle: experimental study of the sublimation of ice through a fine-grained basaltic regolith. Icarus $\mathbf{1 9 6}(2)$, 446-458 (2008)

J.L. Campbell, G.M. Perrett, R. Gellert, S.M. Andrushenko, N.I. Boyd, J.A. Maxwell, P.L. King, C.D.M. Schofield, Calibration of the Mars Science Laboratory Alpha Particle X-ray Spectrometer. Space Sci. Rev., 1-22 (2012)

V.F. Chevrier, T.S. Altheide, Low temperature aqueous ferric sulfate solutions on the surface of Mars. Geophys. Res. Lett. 35(22), 22101 (2008)

V.F. Chevrier, J. Hanley, T. Altheide, Correction to "Stability of perchlorate hydrates and their liquid solutions at the Phoenix landing site, Mars". Geophys. Res. Lett. 36, 18204 (2009)

P.R. Christensen, Formation of recent Martian gullies through melting of extensive water-rich snow deposits. Nature 422(6927), 45-48 (2003)

B.C. Clark, Implications of abundant hygroscopic minerals in the Martian regolith. Icarus 34(3), 645-665 (1978)

B.C. Clark, D.C. Van Hart, The salts of Mars. Icarus 45(2), 370-378 (1981)

F. Costard, F. Forget, N. Mangold, J. Peulvast, Formation of recent Martian debris flows by melting of nearsurface ground ice at high obliquity. Science 295(5552), 110 (2002)

C.M. Dundas, A.S. McEwen, S. Diniega, S. Byrne, S. Martinez-Alonso, New and recent gully activity on Mars as seen by HiRISE. Geophys. Res. Lett 37 (2010)

K.S. Edgett, R.A. Yingst, M.A. Ravine, M.A. Caplinger, J.N. Maki, F.T. Ghaemi, J.A. Schaffner, J.F. Bell, L.J. Edwards, K.E. Herkenhoff, et al., Curiositys Mars Hand Lens Imager (MAHLI) investigation. Space Sci. Rev., 1-59 (2012)

C.B. Farmer, Liquid water on Mars. Icarus 28(2), 279-289 (1976)

W.C. Feldman, T.H. Prettyman, S. Maurice, J.J. Plaut, D.L. Bish, D.T. Vaniman, M.T. Mellon, A.E. Metzger, S.W. Squyres, S. Karunatillake, et al., Global distribution of near-surface hydrogen on Mars. J. Geophys. Res. 109 (2004) 
J. Ferris, J. Dohm, V. Baker, T. Maddock III, Dark slope streaks on Mars-are aqueous processes involved? Geophys. Res. Lett. 29(10), 128 (2002)

F. Forget, F. Hourdin, R. Fournier, C. Hourdin, O. Talagrand, M. Collins, S.R. Lewis, P.L. Read, J.P. Huot, Improved general circulation models of the Martian atmosphere from the surface to above $80 \mathrm{~km}$. J. Geophys. Res. 104(24), 24-155 (1999)

E.J. Gaidos, Cryovolcanism and the recent flow of liquid water on Mars. Icarus 153(1), 218-223 (2001)

J.M. Goldspiel, S.W. Squyres, Groundwater discharge and gully formation on Martian slopes. Icarus 211(1), 238-258 (2011)

J. Gómez-Elvira, C. Armiens, L. Castañer, M. Domínguez, M. Genzer, F. Gómez, R.M. Haberle, A.M. Harri, V. Jiménez, H. Kahanpää, et al., REMS: the environmental sensor suite for the Mars Science Laboratory rover. Space Sci. Rev., 1-58 (2012)

R. Gough, V. Chevrier, K. Baustian, M. Wise, M. Tolbert, Laboratory studies of perchlorate phase transitions: Support for metastable aqueous perchlorate solutions on Mars. Earth Planet. Sci. Lett. 312(3), 371-377 (2011)

J.P. Grotzinger, J. Crisp, A.R. Vasavada, R.C. Anderson, C.J. Baker, R. Barry, D.F. Blake, P. Conrad, K.S. Edgett, B. Ferdowski, et al., Mars Science Laboratory mission and science investigation. Space Sci. Rev., 1-52 (2012)

E. Grün, J. Gebhard, A. Bar-Nun, J. Benkhoff, H. Düren, G. Eich, R. Hische, W.F. Huebner, H.U. Keller, G. Klees, et al., Development of a dust mantle on the surface of an insolated ice-dust mixture: results from the KOSI-9 experiment. J. Geophys. Res. 98(E8), 15091-15104 (1993)

R.M. Haberle, C.P. McKay, J. Schaeffer, A.P. Zent, N.L. Cabrol, E.A. Grin, R. Quinn, On the possibility of liquid water on present-day Mars. J. Geophys. Res. 106(23), 317-323 (2001)

R.M. Haberle, N. Renno, M.I. Richardson, H. Savijärvi, J. Schaeffer, D. Tyler, A.R. Vasavada (The REMS Team), Meteorological predictions for the REMS experiment on MSL. Space Sci. Rev. (2012, in press)

C. Hansen, M. Bourke, N. Bridges, S. Byrne, C. Colon, S. Diniega, C.M. Dundas, K. Herkenhoff, A. McEwen, M. Mellon, et al., Seasonal erosion and restoration of Mars' northern polar dunes. Science 331(6017), 575 (2011)

G.B. Hansen, Control of the radiative behavior of the Martian polar caps by surface $\mathrm{CO}_{2}$ ice: evidence from Mars Global Surveyor measurements. J. Geophys. Res. 104(E7), 16416-16486 (1999)

W.K. Hartmann, Martian seeps and their relation to youthful geothermal activity. Space Sci. Rev. 96(1), 405410 (2001)

M.H. Hecht, Metastability of liquid water on Mars. Icarus 156(2), 373-386 (2002)

M. Hecht, S. Kounaves, R. Quinn, S. West, S. Young, D. Ming, D. Catling, B. Clark, W. Boynton, J. Hoffman, et al., Detection of perchlorate and the soluble chemistry of Martian soil at the Phoenix lander site. Science 325(5936), 64 (2009)

J.L. Heldmann, E. Carlsson, H. Johansson, M.T. Mellon, O.B. Toon, Observations of Martian gullies and constraints on potential formation mechanisms, II: the northern hemisphere. Icarus 188(2), 324-344 (2007)

N. Hoffman, Active polar gullies on Mars and the role of carbon dioxide. Astrobiology 2(3), 313-323 (2002)

C.H. Hugenholtz, Frosted granular flow: A new hypothesis for mass wasting in Martian gullies. Icarus 197(1), 65-72 (2008)

E. Jones, C. Lineweaver, Using the phase diagram of liquid water to search for life. Aust. J. Earth Sci. 59(2), 253-262 (2012)

E. Kaufmann, N.I. Kömle, G. Kargl, Laboratory simulation experiments on the solid-state greenhouse effect in planetary ices. Icarus 185(1), 274-286 (2006)

H. Keller, W. Goetz, H. Hartwig, S. Hviid, R. Kramm, W. Markiewicz, R. Reynolds, C. Shinohara, P. Smith, R. Tanner, et al., Phoenix robotic arm camera. J. Geophys. Res. 113(E3), 0017 (2008)

A. Kereszturi, M. Vincendon, F. Schmidt, Water ice in the dark dune spots of Richardson crater on Mars. Planet. Space Sci. 59(1), 26-42 (2011)

A. Kereszturi, D. Möhlmann, S. Berczi, T. Ganti, A. Kuti, A. Sik, A. Horvath, Recent rheologic processes on dark polar dunes of Mars: driven by interfacial water? Icarus 201(2), 492-503 (2009)

A. Kereszturi, D. Möhlmann, S. Berczi, T. Ganti, A. Horvath, A. Kuti, A. Sik, E. Szathmary, Indications of brine related local seepage phenomena on the northern hemisphere of Mars. Icarus 207(1), 149-164 (2010)

H.H. Kieffer, Cold jets in the Martian polar caps. J. Geophys. Res. 112, 08005 (2007)

C. King, N. Schorghofer, K. Wagstaff, Martian slope streaks form sporadically throughout the year, in Lunar and Planetary Institute Science Conference Abstracts, vol. 41, 2010, p. 1542

M.A. Kreslavsky, J.W. Head, Slope streaks on Mars: a new "wet” mechanism. Icarus 201(2), 517-527 (2009)

P.R. Mahaffy, C.R. Webster, M. Cabane, P.G. Conrad, P. Coll, S.K. Atreya, R. Arvey, M. Barciniak, M. Benna, L. Bleacher, et al., The sample analysis at Mars investigation and instrument suite. Space Sci. Rev., 1-78 (2012) 
J. Maki, D. Thiessen, A. Pourangi, P. Kobzeff, T. Litwin, L. Scherr, S. Elliott, A. Dingizian, M. Maimone, The Mars Science Laboratory engineering cameras. Space Sci. Rev., 1-17 (2012)

M.C. Malin, K.S. Edgett, Evidence for recent groundwater seepage and surface runoff on Mars. Science 288(5475), 2330 (2000)

M.C. Malin, K.S. Edgett, L.V. Posiolova, S.M. McColley, E.Z.N. Dobrea, Present-day impact cratering rate and contemporary gully activity on Mars. Science 314(5805), 1573 (2006)

G.M. Martinez, N.O. Renno, H.M. Eliott, The evolution of the albedo of dark spots observed on Mars polar region. Icarus 221, 816-830 (2012)

P. Masson, M.H. Carr, F. Costard, R. Greeley, E. Hauber, R. Jaumann, Geomorphologic evidence for liquid water. Space Sci. Rev. 96(1), 333-364 (2001)

S. Maurice, R. Wiens, M. Saccoccio, B. Barraclough, O. Gasnault, O. Forni, N. Mangold, D. Baratoux, S. Bender, G. Berger, et al., The ChemCam instrument suite on the Mars Science Laboratory (MSL) rover: science objectives and mast unit description. Space Sci. Rev., 1-72 (2012)

A.S. McEwen, L. Ojha, C.M. Dundas, S.S. Mattson, S. Byrne, J.J. Wray, S.C. Cull, S.L. Murchie, N. Thomas, V.C. Gulick, Seasonal flows on warm Martian slopes. Science 333(6043), 740 (2011)

M. Mehta, N.O. Renno, J. Marshall, M. Rob Grover, A. Sengupta, N.A. Rusche, J.F. Kok, R.E. Arvidson, W.J. Markiewicz, M.T. Lemmon, et al., Explosive erosion during the Phoenix landing exposes subsurface water on Mars. Icarus 211(1), 172-194 (2011)

M.T. Mellon, R.J. Phillips, Recent gullies on Mars and the source of liquid water. J. Geophys. Res. 106(E10), 23165-23180 (2001)

M.T. Mellon, W.C. Feldman, T.H. Prettyman, The presence and stability of ground ice in the southern hemisphere of Mars. Icarus 169(2), 324-340 (2004)

M.T. Mellon, R.E. Arvidson, H.G. Sizemore, M.L. Searls, D.L. Blaney, S. Cull, M.H. Hecht, T.L. Heet, H.U. Keller, M.T. Lemmon, et al., Ground ice at the phoenix landing site: stability state and origin. J. Geophys. Res. 114(E1), 0007 (2009)

J.A. Mikucki, A. Pearson, D.T. Johnston, A.V. Turchyn, J. Farquhar, D.P. Schrag, A.D. Anbar, J.C. Priscu, P.A. Lee, A contemporary microbially maintained subglacial ferrous "ocean". Science 324(5925), 397400 (2009)

R.E. Milliken, J.P. Grotzinger, B.J. Thomson, Paleoclimate of Mars as captured by the stratigraphic record in Gale Crater. Geophysical Research Letters 37, (2010)

I. Mitrofanov, M. Litvak, A. Kozyrev, A. Sanin, V. Tretyakov, V.Y. Grinkov, W. Boynton, C. Shinohara, D. Hamara, R. Saunders, Soil water content on Mars as estimated from neutron measurements by the HEND instrument onboard the 2001 Mars Odyssey spacecraft. Sol. Syst. Res. 38(4), 253-257 (2004)

I. Mitrofanov, M. Litvak, A. Varenikov, Y. Barmakov, A. Behar, Y. Bobrovnitsky, E. Bogolubov, W. Boynton, K. Harshman, E. Kan, et al., Dynamic Albedo of Neutrons (DAN) Experiment onboard NASA's Mars Science Laboratory. Space Sci. Rev., 1-24 (2012)

D. Möhlmann, Water in the upper martian surface at mid-and low-latitudes: presence, state, and consequences. Icarus 168(2), 318-323 (2004)

D. Möhlmann, Adsorption water-related potential chemical and biological processes in the upper Martian surface. Astrobiology 5(6), 770-777 (2005)

D. Möhlmann, The influence of van der Waals forces on the state of water in the shallow subsurface of Mars. Icarus 195(1), 131-139 (2008)

D. Möhlmann, Temporary liquid water in upper snow/ice sub-surfaces on Mars? Icarus 207(1), 140-148 (2010)

D. Möhlmann, Latitudinal distribution of temporary liquid cryobrines on Mars. Icarus 214, 236-239 (2011a)

D. Möhlmann, Three types of liquid water in icy surfaces of celestial bodies. Planet. Space Sci. 59(10), 1082-1086 (2011b)

D. Möhlmann, A. Kereszturi, Viscous liquid film flow on dune slopes of Mars. Icarus 207(2), 654-658 (2010)

D. Möhlmann, K. Thomsen, Properties of cryobrines on Mars. Icarus 212(1), 123-130 (2011)

J.M. Moore, M.A. Bullock, Experimental studies of Mars-analog brines. J. Geophys. Res. 104, 21 (1999)

S. Murchie, R. Arvidson, P. Bedini, K. Beisser, J. Bibring, J. Bishop, J. Boldt, P. Cavender, T. Choo, R. Clancy, et al., Compact Reconnaissance Imaging Spectrometer for Mars (CRISM) on Mars Reconnaissance Orbiter (MRO). J. Geophys. Res. 112 (2007)

M. Osterloo, V. Hamilton, J. Bandfield, T. Glotch, A. Baldridge, P. Christensen, L. Tornabene, F. Anderson, Chloride-bearing materials in the southern highlands of Mars. Science 319(5870), 1651-1654 (2008)

S.M. Pelkey, B.M. Jakosky, P.R. Christensen, Surficial properties in Gale Crater, Mars, from Mars Odyssey Themis data. Icarus 167(2), 244-270 (2004)

D.K. Perovich, Light reflection from sea ice during the onset of melt. J. Geophys. Res. 99(C2), 3351-3359 (1994)

M. Rao, S. Sutton, D. McKay, G. Dreibus, Clues to Martian brines based on halogens in salts from nakhlites and MER samples. J. Geophys. Res. 110(E12), 1206 (2005) 
N.O. Rennó, M. Mehta, B.P. Block, S. Braswell, The Discovery of Liquid Water on Mars and Its Implications for Astrobiology, in Proceedings of SPIE, vol. 7441 (2009a), p. 74410

N.O. Rennó, B.J. Bos, D. Catling, B.C. Clark, L. Drube, D. Fisher, W. Goetz, S.F. Hviid, H.U. Keller, J.F. Kok, et al., Possible physical and thermodynamical evidence for liquid water at the Phoenix landing site. J. Geophys. Res. 114(E1), 0003 (2009b)

E. Rivkina, E. Friedmann, C. McKay, D. Gilichinsky, Metabolic activity of permafrost bacteria below the freezing point. Appl. Environ. Microbiol. 66(8), 3230-3233 (2000)

H. Savijärvi, A. Määttänen, Boundary-layer simulations for the Mars Phoenix lander site. Q. J. R. Meteorol. Soc. 136(651), 1497-1505 (2010)

J. Seinfeld, S. Pandis, Atmospheric Chemistry and Physics: From Air Pollution to Climate Change (Wiley, New York, 2006)

M.D. Smith, Interannual variability in TES atmospheric observations of Mars during 1999-2003. Icarus 167(1), 148-165 (2004)

R. Sullivan, P. Thomas, J. Veverka, M. Malin, K.S. Edgett, Mass movement slope streaks imaged by the Mars Orbiter Camera. J. Geophys. Res. 106(E10), 23607 (2001)

P.A. Taylor, K. Baibakov, S. Brown, M.H. Hecht, T.L. Hudson, P.Y. Li, C.F. Lange, L. Prieto, S. Savelyev, On the sublimation of ice particles on the surface of Mars; with applications to the 2007/8 Phoenix Scout mission. Icarus 181(2), 375-387 (2006)

A.H. Treiman, Geologic settings of Martian gullies: implications for their origins. J. Geophys. Res. 108(E4), 8031 (2003)

K. Williams, O. Toon, J. Heldmann, M. Mellon, Ancient melting of mid-latitude snowpacks on Mars as a water source for gullies. Icarus 200(2), 418-425 (2009)

A.P. Zent, M.H. Hecht, D.R. Cobos, S.E. Wood, T.L. Hudson, S.M. Milkovich, L.P. DeFlores, M.T. Mellon, Initial results from the thermal and electrical conductivity probe (TECP) on Phoenix. J. Geophys. Res. 115, 0014 (2010)

M.P. Zorzano, E. Mateo-Martí, O. Prieto-Ballesteros, S. Osuna, N. Renno, Stability of liquid saline water on present day Mars. Geophys. Res. Lett. 36(20), 20201 (2009) 